\section{Beef quality program meets evolving consumer and producer concerns}

alifornia is the sixth-largest beef-producing state in the country, with more than 1 million animals sent to slaughter in 2004. Although large producers are still the backbone of the state's commercial beef industry, more than $50 \%$ of the state's beef cattle are produced in herds of less than 50 animals. Ironically, as California continues to urbanize, the number of small herd operators is predicted to increase as the number of mid-sized operations declines.

Consumer preferences and health concerns are among the key factors driving the nation's beef industry. California was one of the first states in the nation to offer a comprehensive series of educational programs for the full spectrum of beef production - from the hobby farmer with a few head to large feedlots shipping overseas.

James Oltjen, Cooperative Extension animal scientist at UC Davis, helped to develop the state's first beef quality assurance program (QAP) more than a dozen years ago. "Through this program we've made a lot of cattle healthier and shown thousands of people how to give proper injections to their livestock," Oltjen says.

Most of California's cow-calf producers have participated in at least one component of a QAP developed cooperatively by UC Cooperative Extension (UCCE) and industry trade groups. This voluntary effort continues to make a significant difference in animal husbandry practices that ultimately lead to improved beef quality, greater consumer satisfaction and more producer profitability.

QAP evolves to meet industry needs. Following a successful educational effort begun with California feedlots in 1990, a survey of producers, feeders, packers, veterinarians and others in the industry led to the formation of a cow-calf quality assurance committee by the California Cattlemen's Association in 1992. About the same time, the National Cattlemen's Association identified a number of management-related quality problems such as injection-site blemishes, hide damage, bruises and carcass condemnations that were costing the industry $\$ 700$ million a year.

Formal trainings with UCCE veterinarians and animal scientists began in 1993. Improperly administered injections are one of the chief concerns

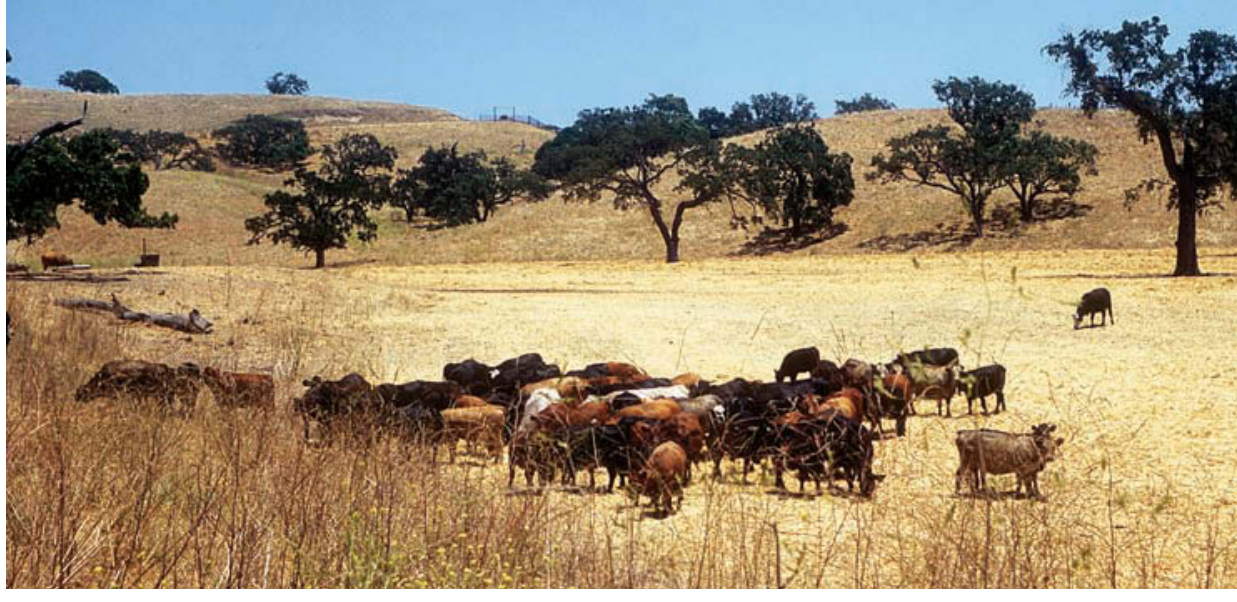

More than $\mathbf{5 0 \%}$ of California's beef cattle are produced in small herds of $\mathbf{5 0}$ animals or less. UC beef quality assurance programs have improved cattle health and increased the competitiveness of California beef in national markets. Cattle graze in the Santa Ynez Valley of northern Santa Barbara County.

because damaged tissue is tough and if noticed before sale must be disposed of during processing. Producers learn to avoid such losses by using subcutaneous injections instead of intramuscular injections; mixing an hour's worth of vaccine at a time; injecting vaccines and antibiotics in the neck, instead of the hindquarters; changing needles more frequently; and limiting the volume of animal health products injected into any one site.

QAP trainings are held on demand from county cattlemen's organizations at ranches, sale barns, fairgrounds and occasionally the UC Sierra Foothill Research and Extension Center. When the program was first initiated, trainings were held throughout the state. Now, about four of them are presented each year. The 4-hour basic course includes lectures, videos and accountability quizzes. In addition to needle and injection-site preferences, attendees learn about sanitation, how to understand drug labels, record-keeping, transportation, animal handling and facility design.

"The beef industry needs to assure the consumer that the beef he or she is buying is safe and wholesome and grown with consideration for the animal's welfare," Oltjen says. "The packers want meat that will not have injection sites or excessive bruises that have to be removed or condemned. The quality assurance program is a seal of approval that producers know how to prevent these defects."

Bill Sanguinetti, a cattle rancher in San Joaquin County, says the start of the QAP marked the beginning of an industry revolution. "That's when the beef industry became more consumer-oriented, rather than strictly production-oriented," he says. "It started at the national level with a lot of farsighted people who saw the need to educate producers to address inconsistency and other quality problems." 


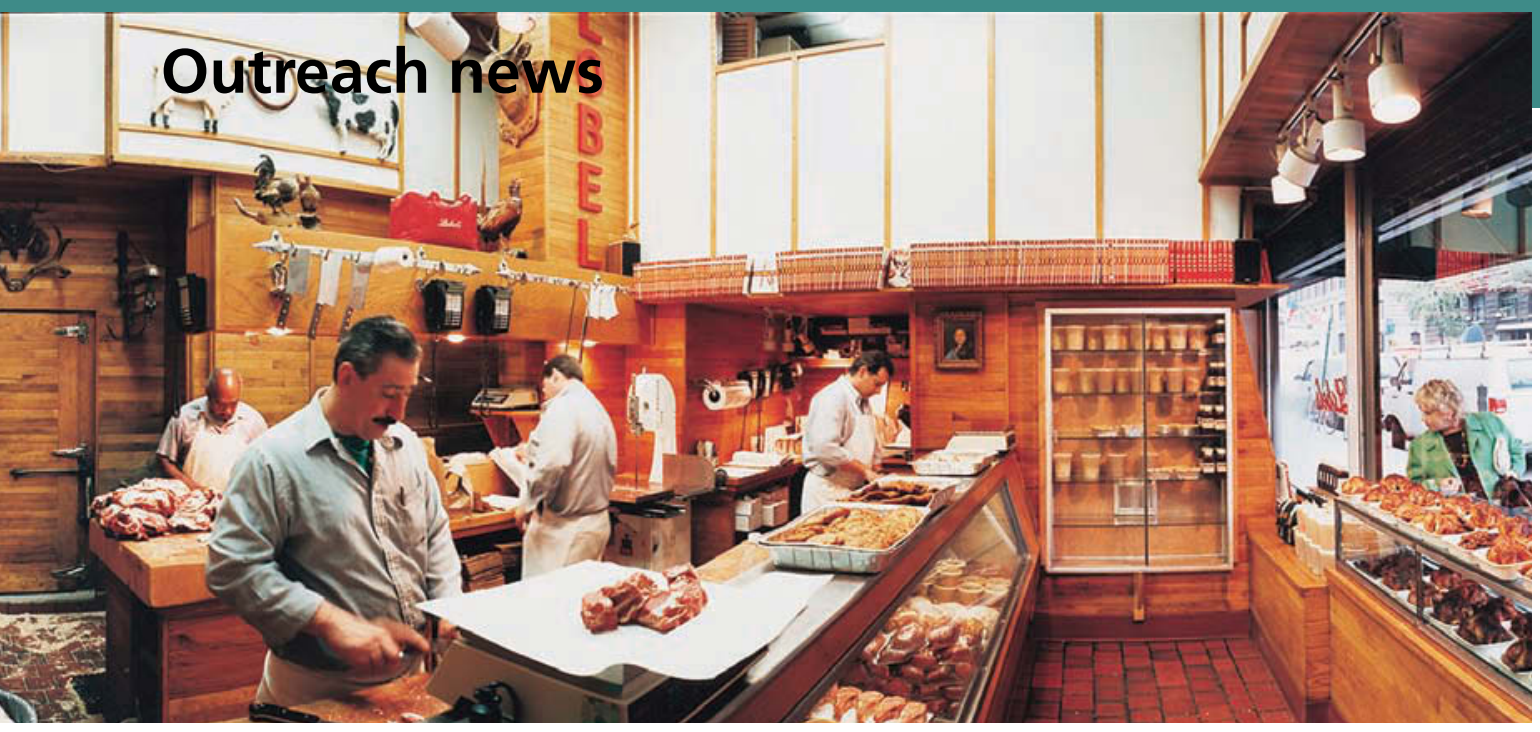

California beef producers are increasingly taking advantage of opportunities to provide higherquality products for premium prices. Specialty butcher shops such as Lobel's in New York City will ship high-end beef all over the country, for a price.

Judging from the feedback he's gotten, Sanguinetti believes the program has been a success. "We've heard from the packers that there's been a marked increase in carcass quality. This is a field-to-fork system and the strong beef demand tells me it's working."

About 5,000 participants have taken the basic cow-calf program since October 17, 1993, when UCCE farm advisor Roger Ingram held the first workshop for about 100 local cow-calf producers in the once-rural Placer County community of Lincoln. Since this original program is only 4 hours long, three additional advanced programs with more in-depth information have been offered and another is in development.

Advanced programs offered. According to industry trade groups, the primary factor affecting beef's cost competitiveness with other protein sources is excess carcass fat. This concern led to the development of a program on advanced genetics and value-based marketing. Producers learn the basics of beef genetics, including bull selection, the use of ultrasound technology and carcass quality. The program also teaches producers how to match cattle types to the area in which they will be raised and how to manipulate breeding systems to their advantage. First offered in 1995, more than 380 producers had taken the advanced genetics and valuebased marketing course.

The advanced residue avoidance and reproduction program, begun in 2000, has been one of the most popular with 564 attendees in 14 sessions through November 2004. This program provides indepth information on pharmacokinetics, anatomy, estrous cycle, reproductive technology, maximizing calf production and symptoms of reproductive problems. Breakout sessions cover proper medication administration, drug-use regulations, bodycondition scoring and nutrition, artificial insemination and estrous synchronization, prevention of calving problems, bull breeding soundness, and recordkeeping and computer programs.
The advanced animal health program was designed in 1994 to teach producers how to focus on diseases common to a specific region. Twelve of these programs have been held so far with more than 460 attendees.

Finally, a program in development will acquaint producers with new technology designed to track individual animals to improve management and to address concerns about transmissible animal diseases such as foot and mouth and bovine spongiform encephalopathy (BSE, or "mad cow disease"). This program will show producers how to participate in a new animal identification system proposed by the U.S. Department of Agriculture.

"It's a very ambitious program that USDA is developing," says UCCE veterinarian John Maas, co-author of educational materials for the quality-assurance trainings. Through a microchip embedded in an ear tag, Maas says, animals will be traceable through the ranches, feedlots and packinghouses they pass through along the way to the consumer.

Industry trends. The beef industry is moving toward increasing accountability, and those who embrace such changes are being rewarded, Maas says. Producers who have voluntarily adopted radio frequency identification (RFID) technology to "trace back" cattle are receiving premiums from large retail end users such as McDonald's.

In addition, name-brand beef such as Harris Ranch is more evident in supermarkets throughout California. And boutique butcher shops such as Lobel's of New York can overnight vacuum-sealed, high-end beef across the country to consumers willing to pay the price.

"It's beyond safety," Maas says. "What's happening in the beef industry is similar to what happened with microbreweries. Consumers want to know where their food comes from. They want to know it's local and there's a real person standing behind it."

- John Stumbos 